\title{
Reflections on public health surveillance of pandemic (H1N1) 2009 influenza in NSW
}

\section{Tim Churches ${ }^{\mathrm{A}}$, Stephen J. Conaty ${ }^{\mathrm{B}}$, Robin E. Gilmour ${ }^{\mathrm{C}, \mathrm{D}}$ and David J. Muscatello ${ }^{\mathrm{A}}$}

${ }^{\mathrm{A}}$ Centre for Epidemiology and Research, NSW Department of Health

${ }^{B}$ Public Health Unit, Sydney South West Area Health Service

${ }^{\mathrm{C}}$ Communicable Diseases Branch, NSW Department of Health

${ }^{\mathrm{D} C o r r e s p o n d i n g ~ a u t h o r . ~ E m a i l: ~ r o b i n . g i l m o u r @ ~}$

doh.health.nsw.gov.au

\begin{abstract}
Surveillance has a fundamental role during public health emergencies to provide accurate and relevant information to guide decision making. For each phase of the NSW response to the pandemic H1N1 (2009) influenza there were significant differences in the public health surveillance objectives and response mechanisms. Consequently each phase placed a different emphasis on the various sources and types of surveillance information which were collected and reported upon. We examine whether the NSW public health surveillance systems were able to inform effective public health management throughout all phases of the pandemic (H1N1) 2009 influenza.
\end{abstract}

Australian health authorities have for many years undertaken extensive planning for an influenza pandemic. The Australian approach to pandemic influenza has always had as its centrepiece the goals of delay and containment of spread through border control coupled with the active follow-up of early cases, their isolation and treatment with oseltamivir, together with the quarantining and prophylaxis of close contacts of those cases. For the success of these plans, importance was attached to the timely identification of early cases, both those arriving from affected areas overseas, and those arising from early local transmission. Implicit in the plans was the existence of efficient and high capacity mechanisms to effect the public health control measures of isolation, quarantine and antiviral treatment or prophylaxis for each case or contact. ${ }^{1}$
In April 2009, a new influenza A virus (pandemic [H1N1] 2009 influenza) was isolated in California ${ }^{2}$ and subsequently linked to earlier cases of respiratory illness beginning in March in Mexico City and February in Veracruz. ${ }^{3,4}$ On 27 April the World Health Organization (WHO) declared pandemic phase 4 . Within a matter of weeks the virus was known to have spread to at least two other countries. On 25 April, in response, the NSW Department of Health opened its Public Health Emergency Operations Centre (PHEOC) and on 28 April announced the commencement of the DELAY phase of the National Pandemic Action Plan. Three weeks later, sustained community transmission of the virus within Australia was confirmed, and on 22 May a move to the CONTAIN phase was announced nationally. On 17 June, less than 2 weeks later, Australia moved to the PROTECT phase, which had not been foreshadowed in prior plans. There were significant differences in the public health surveillance objectives and response mechanisms for each of these phases.

In this article we examine whether NSW public health surveillance systems provided the information required to effectively drive public health action and inform critical public health policy decisions during each of these phases. Our approach to this task is to ask the following questions: What did we want our surveillance systems to tell us? Did they tell us what we wanted to know? What was missing or what could we have done better?

The surveillance systems used during the pandemic (H1N1) influenza response are described in Box 1. The surveillance findings for pandemic (H1N1) 2009 influenza in NSW have been reported in detail elsewhere 5 and will not be repeated here.

\section{DELAY phase \\ Case definition}

The initial surveillance and control case definition for suspected cases, adopted on 30 April 2009, was: a person with an acute febrile respiratory illness, with onset within 7 days of close contact with a person who is a confirmed or an influenza A-positive suspect case of pandemic (H1N1) 2009 influenza virus infection; or onset since 15 April 2009 and within 7 days of travel to Mexico, the USA or Canada. Japan and Panama were added to this list of affected regions on 23 May, and Chile, Argentina and greater metropolitan Melbourne were added on 15 June. 
Box 1. Summary of surveillance systems used during the NSW pandemic (H1N1) 2009 influenza response

\begin{tabular}{|c|c|c|c|c|}
\hline $\begin{array}{l}\text { Surveillance } \\
\text { system/tool }\end{array}$ & Aim & $\begin{array}{l}\text { Existing/ } \\
\text { New }\end{array}$ & $\begin{array}{l}\text { Operation } \\
\text { (in phases) }\end{array}$ & Comments \\
\hline $\begin{array}{l}\text { Notifiable } \\
\text { Diseases Database }\end{array}$ & $\begin{array}{l}\text { Monitoring confirmed influenza } \\
\text { infections in the population }\end{array}$ & Existing & DELAY & $\begin{array}{l}\text { Initially no laboratory test specific for the pandemic } \\
\text { strain was available, thus cases not able to be } \\
\text { notified. Existing laboratory notification system } \\
\text { still paper-based. A faster electronic notification } \\
\text { system had been under construction for several } \\
\text { years but was not ready for deployment. }\end{array}$ \\
\hline NetEpi & $\begin{array}{l}\text { To collect demographic, } \\
\text { epidemiolgical, laboratory result } \\
\text { and public health response } \\
\text { information of all cases and } \\
\text { contacts presenting with } \\
\text { influenza-like illness, and to } \\
\text { assign case status once known }\end{array}$ & Existing & $\begin{array}{l}\text { DELAY, } \\
\text { CONTAIN and } \\
\text { PROTECT }\end{array}$ & $\begin{array}{l}\text { NetEpi software was used at a national level } \\
\text { to collate case data from each state and } \\
\text { territory. NSW used its own instance of } \\
\text { NetEpi. Information recorded was available } \\
\text { immediately and centrally for analysis. } \\
\text { Information could be recorded in many } \\
\text { different sites and types of sites, such as } \\
\text { regional public health units and public } \\
\text { health laboratories. Changing case } \\
\text { definitions, delays in disseminating case } \\
\text { definitions and changing policy and data } \\
\text { collection priorities presented the greatest } \\
\text { challenge for managing the system. Most } \\
\text { users found it easy to use, even with } \\
\text { minimal or no training. }\end{array}$ \\
\hline $\begin{array}{l}\text { Seasonal influenza } \\
\text { laboratory } \\
\text { surveillance }\end{array}$ & $\begin{array}{l}\text { Collect aggregate data from major } \\
\text { laboratories on number and results } \\
\text { of respiratory viruses tested }\end{array}$ & Existing & $\begin{array}{l}\text { DELAY, } \\
\text { CONTAIN and } \\
\text { PROTECT }\end{array}$ & $\begin{array}{l}\text { Initially, no test for the virus although one was } \\
\text { developed quickly. The two main public sector } \\
\text { laboratories involved became rapidly overwhelmed. }\end{array}$ \\
\hline $\begin{array}{l}\text { Emergency } \\
\text { Department (ED) } \\
\text { surveillance }\end{array}$ & $\begin{array}{l}\text { Twice daily assessment of the } \\
\text { number of ED presentations } \\
\text { with an assigned diagnosis of } \\
\text { general respiratory illness }\end{array}$ & Existing & $\begin{array}{l}\text { DELAY, } \\
\text { CONTAIN and } \\
\text { PROTECT }\end{array}$ & $\begin{array}{l}\text { In DELAY and CONTAIN phases the ED } \\
\text { data was influenced by the public health } \\
\text { response which advised people who may } \\
\text { have been exposed to the virus to attend } \\
\text { EDs, even if not unwell. Media } \\
\text { attention may have influenced the } \\
\text { propensity of clinicians to use the } \\
\text { influenza-like illness diagnosis. Was useful } \\
\text { in later stages for assessing activity at the } \\
\text { population level, although media advice } \\
\text { was for people to attend EDs rather than } \\
\text { GPs. Therefore, results may have been } \\
\text { somewhat biased. On the other hand, given } \\
\text { the inconvenience of attending a hospital, } \\
\text { people may have been reluctant to go to a } \\
\text { hospital unless their symptoms justified it. }\end{array}$ \\
\hline $\begin{array}{l}\text { Airport arrival } \\
\text { screening }\end{array}$ & $\begin{array}{l}\text { Assessment of all incoming } \\
\text { overseas passengers for } \\
\text { influenza-like illness }\end{array}$ & New & $\begin{array}{l}\text { DELAY and } \\
\text { CONTAIN }\end{array}$ & $\begin{array}{l}\text { Reliant on people having symptoms at } \\
\text { time of arrival and reporting those symptoms. } \\
\text { Due to the overall mildness of disease, } \\
\text { some infected people may not have met the } \\
\text { case definition. People also presented regardless } \\
\text { of whether they had been in affected countries, } \\
\text { therefore increasing the triage workload. }\end{array}$ \\
\hline $\begin{array}{l}\text { Ambulance } \\
\text { dispatch } \\
\text { surveillance }\end{array}$ & $\begin{array}{l}\text { Daily assessment of the number of } \\
\text { ambulances being dispatched, } \\
\text { particularly for certain problems } \\
\text { such as 'breathing problems' }\end{array}$ & Existing & $\begin{array}{l}\text { DELAY and } \\
\text { CONTAIN }\end{array}$ & $\begin{array}{l}\text { As there was not a specific policy relating to } \\
\text { use of ambulances at any stage, this may be } \\
\text { the least biased surveillance source. }\end{array}$ \\
\hline $\begin{array}{l}\text { Influenza clinic } \\
\text { surveillance }\end{array}$ & $\begin{array}{l}\text { Record daily aggregated } \\
\text { influenza clinic activity }\end{array}$ & New & PROTECT & $\begin{array}{l}\text { Diverse patient management information } \\
\text { systems used in clinics meant that there } \\
\text { was some overlap between flu clinic } \\
\text { surveillance and ED surveillance. Difficult to } \\
\text { avoid double counting of patients in both } \\
\text { ED and clinic surveillance systems in some } \\
\text { hospitals. }\end{array}$ \\
\hline $\begin{array}{l}\text { Intensive care } \\
\text { surveillance }\end{array}$ & $\begin{array}{l}\text { Record daily aggregated } \\
\text { influenza-related } \\
\text { intensive care unit activity }\end{array}$ & New & PROTECT & $\begin{array}{l}\text { In addition, a research-oriented data collection } \\
\text { captured detailed clinical characteristics of } \\
\text { intensive care unit patients. }\end{array}$ \\
\hline $\begin{array}{l}\text { Pneumonia and } \\
\text { influenza mortality } \\
\text { surveillance }\end{array}$ & $\begin{array}{l}\text { Information on all cause mortality } \\
\text { and excess pneumonia and } \\
\text { influenza deaths from the } \\
\text { NSW Registry of Births, Deaths } \\
\text { and Marriages }\end{array}$ & $\begin{array}{l}\text { Existing, } \\
\text { enhanced to } \\
\text { provide data } \\
\text { updates }\end{array}$ & $\begin{array}{l}\text { DELAY, } \\
\text { CONTAIN and } \\
\text { PROTECT }\end{array}$ & $\begin{array}{l}\text { Valuable for assessing the severity and impact } \\
\text { of the epidemic. }\end{array}$ \\
\hline $\begin{array}{l}\text { General practitioner } \\
\text { sentinel surveillance } \\
\text { (GPSS) }\end{array}$ & $\begin{array}{l}\text { Aggregate information } \\
\text { on the number of people } \\
\text { with influenza-like } \\
\text { illness presenting to } \\
\text { 'sentinel' GPs, with a } \\
\text { subset of patients tested } \\
\text { for influenza }\end{array}$ & New & PROTECT & $\begin{array}{l}\text { This was never planned for and was developed } \\
\text { over a two week period. It was in hindsight } \\
\text { established too late. However, the GPSS did } \\
\text { highlight an ability to capture community } \\
\text { spread and severity. Further evaluation is } \\
\text { required to determine the usefulness of such } \\
\text { a surveillance system. }\end{array}$ \\
\hline $\begin{array}{l}\text { Absentee data } \\
\text { surveillance }\end{array}$ & $\begin{array}{l}\text { Provided data on workers } \\
\text { absent for more than } 3 \text { days } \\
\text { from a large, widely } \\
\text { geographically distributed, } \\
\text { non-health sector organisation }\end{array}$ & New & PROTECT & Further evaluation required. \\
\hline
\end{tabular}




\section{Surveillance methods used}

Border screening

The primary method for operationalising this case definition during the DELAY phase was through the use of border health declaration cards, first issued on 6 May to incoming international aircraft passengers who were required to self-declare symptoms and relevant potential exposures. Thermal imaging scanners had also been introduced at all international airports in Australia and were used to detect passengers with a raised temperature. Sydney International Airport handles an average of 4000 passengers each hour, ${ }^{6}$ making the individual clinical assessment of every incoming passenger infeasible. Incoming passengers who self-declared symptoms or relevant exposure, and passengers who were detected by thermal imaging scanners were assessed at the airport by public health staff to determine whether they met the case definition. If they did, nose and throat swabs were taken, followed by home isolation of the case and quarantine of close contacts until the diagnosis was excluded based on a negative swab result or until the potentially infectious period had passed.

Extensive media warnings for the general public were also issued asking people who had symptoms to call their local doctor and if necessary, were referred to an Emergency Department for assessment.

During the DELAY and CONTAIN phases, the relevant identifying, demographic, exposure and health assessment data were captured in real time in NetEpi, ${ }^{7}$ using wireless internet connectivity available at the airport. NetEpi was also used to record epidemiological, laboratory result and case management details of both suspected and confirmed cases of pandemic (H1N1) 2009 influenza, as well as relevant details of their close contacts.

NetEpi is an open-source, web-based database system designed for public health response and fieldwork, which was originally developed by NSW Health in response to the global severe acute respiratory syndrome (SARS) epidemic in 2003. It has been incrementally enhanced and refined since then. It allows several hundred authorised personnel in many locations to simultaneously enter and update person-based epidemiological and public health response information in a single, shared database, thus providing instant access to the most recent data at all times. During later response phases, when quarantining of contacts ceased, only the details of confirmed cases were captured.

\section{Public health real-time emergency department surveillance system}

The public health real-time emergency department surveillance system (PHREDSS) was used throughout the response to pandemic (H1N1) 2009 influenza to provide the number of presentations to emergency departments with an influenza like illness. PHREDSS is an existing electronic, syndromic surveillance system which receives and analyses data from the clinical information systems of 52 hospital emergency departments across NSW in near real time. A summary report was produced each day of possible H1N1cases which was then sent to public health units to investigate.

\section{Laboratory surveillance}

The existing laboratory surveillance system provided data on the total number of respiratory samples tested and total samples positive for pandemic (H1N1) 2009 influenza. These data were entered onto NetEpi and were available to all public health staff. Entering results directly into NetEpi allowed for enhanced management of cases and contacts who were under quarantine. Laboratory surveillance has been described in detail in this issue by Adamson and colleagues (pp. 36-38).

\section{Outcome of DELAY phase surveillance}

During the DELAY phase, from 28 April to 22 May, there were 599 incoming passengers assessed at the airport: of these, 43 met the suspect case definition and were entered into NetEpi and placed in isolation. During the same period, details of approximately 280 additional people who also met the suspect case criteria were notified from various sources in the community, including general practitioners (GPs), emergency departments and via a NSW Health enquiry line/call centre, which also used NetEpi to capture the details of callers. Approximately 40 people who were close contacts of suspect cases were placed in quarantine during this phase, at least until laboratory results cleared the relevant cases.

In retrospect, the number of incoming air passengers who met the case definition during the DELAY phase appears small. It is unclear whether very few incoming passengers had the infection during this early phase; whether passengers with the infection were failing to declare symptoms or recent travel to affected countries, or both; or whether the case definition itself was overly restrictive. In particular, the case definition required a measured fever of $38^{\circ} \mathrm{C}$, or a good history of fever. ${ }^{8}$ It has been reported recently that only a minority of subjects infected experimentally with seasonal influenza viruses develop fever, ${ }^{9}$ and during the DELAY phase, a WHO report from a school outbreak in Canada suggested that fever was not a defining characteristic of infection by the pandemic virus. ${ }^{10}$

An example of an alternative approach to surveillance and containment is offered by the handling of the arrival of the Pacific Dawn cruise ship in Sydney, as reported in greater detail by Binns and co-authors in this issue (pp. 10-15). In brief, an outbreak of respiratory illness onboard this 
ship was, post disembarkation in Sydney, identified as pandemic (H1N1) 2009 influenza, and an extraordinary effort was made to prevent further spread of the virus by any of the 3000 passengers and crew. The steps taken included voluntary home isolation or quarantine for 7 days of all ship passengers and crew, with daily automated telephone follow-up to encourage the reporting of symptoms of any illness. Close contacts of all suspected and presumed cases, and of 62 confirmed cases, were also quarantined. This response was extremely resource-intensive, but was also extremely successful in preventing transmission to the wider community.

Application of a public health response, at this level of intensity, at short notice, to a significant fraction of incoming air passengers would not be feasible due to the size of the standing public health workforce and the laboratory capacity required. However, the surveillance and response information management tools proved to be scalable, and with further development could potentially help co-ordinate the actions of the massive workforce required.

\section{CONTAIN phase}

The Communicable Diseases Network of Australia (CDNA) Guidelines for the CONTAIN phase ${ }^{11}$ stated that the surveillance objectives were:

- to delay the onset and contain the extent of an H1N1 influenza 2009 epidemic, and thereby provide additional time for the development and administration of a vaccine to the community.

Containment depends on:

- the rapid identification, isolation and treatment of cases, and

- the rapid identification, prophylaxis, quarantine and monitoring of contacts.

- to provide information about effective control and prevention measures, based on:

- data gathered on the natural history of the disease, and factors that influence outcome, and

- the epidemiology of pandemic (H1N1) 2009 influenza in Australia.

As in the DELAY phase, these surveillance objectives were operationalised in the form of a suspect case definition which then drove clinical assessment, laboratory testing, and case registration in NetEpi. This surveillance activity in turn informed the public health actions of isolation, quarantine and, to a lesser extent, school-based interventions.

\section{Case definition}

The suspect case definition employed was relatively unchanged from the DELAY phase. By this stage the case definition had been expanded to include contacts with a confirmed case with more minor symptoms. As previously noted, as the number of cases in Victoria increased in June, the case definition was again changed to include travellers returning from Greater Metropolitan Melbourne.

\section{Limitations of the case definition}

The case definition did not account for the possibility of new introductions of the virus from other countries, nor for possible early community transmission - that is, second or later generation cases which had no connection with overseas travel. This would have required a suspectcase definition without any necessary reference to overseas travel, allied with a suitably specific, sensitive and rapid method of diagnosis, and backed by sufficient clinical assessment and laboratory capacity. To effectively contain (aside from the DELAY phase goal of isolation or quarantine post arrival), we needed to detect very early community transmission. However, the case definitions for the CONTAIN phase sought to detect imported cases rather than detecting early transmission in the community. As mentioned, there were good reasons for this approach, but nevertheless there was a mismatch between the goals for the CONTAIN phase and the case definition actually used. This was, however, unlikely to have had much impact on the epidemic in NSW, since the case definition was also unable to detect infectious people who had no symptoms regardless of their place of origin. Although, in recognition of the potential for community transmission occurring in NSW, sentinel surveillance for cases presenting at emergency departments (PHREDSS) with an influenza-like illness without overseas travel was already in place and being actively monitored.

Community transmission was first reported by GPs in Victoria and then South Australia. ${ }^{12,13}$ In NSW, advice to suspect cases was that they should call their GP or selfpresent to emergency departments rather than presenting to GPs' surgeries. ${ }^{14}$ The reasons for advocating this approach were to discourage the inappropriate collection of swabs as there were scarce laboratory resources, and to protect GPs and practice staff from infection. However, this did not stop GPs from requesting tests for influenza and the volume of tests ordered by GPs was two-fold greater than that ordered by emergency departments. ${ }^{4}$

\section{Surveillance methods used}

The surveillance systems put in place for the DELAY phase were continued during the CONTAIN phase and public health responses focused on tracing cases in the community linked to cases who had travelled, resulting in containment efforts in schools and community settings. The CONTAIN phase lasted a little under 4 weeks, before the PROTECT phase began.

\section{Mapping where cases lived}

During the CONTAIN phase, for the first time ever in NSW, the addresses of cases were geocoded (assigned to exact geographical co-ordinates) in near real time, counts 
of cases aggregated in small areas (Census Collector Districts of about 200 households each, much smaller than postcode or local government areas) and the results made available via an internal web page to authorised personnel as animated high-resolution time-series maps viewable with the popular and free Google Earth software. All these steps were entirely automated, running several times each day without intervention. The animated maps showed the appearance of sporadic cases across NSW, and also showed clear evidence of gradual local spread between contiguous Collector Districts in several locations across rural and regional NSW and in the Sydney metropolitan area. There is potential for such high-resolution, near realtime information to help target surveillance and response efforts more precisely. A future challenge will be to integrate this type of very detailed surveillance information into core public health practice.

\section{PROTECT phase \\ Case definition}

The focus for the PROTECT phase was identifying people who were at greatest risk of severe infection with the aim of providing medical care and interventions to prevent poor outcomes. These were people with: chronic respiratory symptoms, pregnant women, people with morbid obesity, Indigenous people, patients with moderate-tosevere disease with rapid deterioration; and people who had chronic respiratory conditions, cardiac disease, chronic metabolic disease, chronic renal and liver disease, haemoglobinopathies, immunosuppression or chronic neurological conditions. These people were advised to go to emergency departments for assessment.

People who reported only mild symptoms, and who did not meet the vulnerable group criteria were advised to stay at home until better and to consult their local doctor if needed.

In response to evidence of widespread community transmission in Victoria and later elsewhere, a number of measures were discontinued in the PROTECT phase: border screening was abandoned, quarantining of contacts ceased, and laboratory confirmation and treatment of pandemic influenza was reserved for those with severe illness or predisposing underlying conditions. To better use laboratory resources, testing was primarily recommended when it would directly affect patient management or for sentinel surveillance (e.g. GPs and patients admitted to hospitals).

\section{Surveillance methods used \\ Surveillance of hospital presentations}

In order to measure community spread of clinicallydetectable pandemic (H1N1) 2009 infection, different surveillance strategies were needed. PHREDSS continued to be a vital source of surveillance information. It was anticipated that during the PROTECT phase, people with more severe illness would attend emergency departments and thus be captured by the existing emergency department surveillance mechanism.

\section{Influenza clinics}

In pre-pandemic planning, flu clinics were to have been the primary point of contact with the health-care system, and thus the main point of collection for surveillance and monitoring information. However, due to the relatively mild nature of the disease, flu clinics tended to see only an intermittent overflow of patients who presented to emergency departments. Planning had envisaged that a standardised set of data items would be collected about each flu clinic patient, and these data would be collated and analysed promptly to inform health system planning and response. In reality, although a standard paper-based data collection form was made available for use by flu clinics, no mechanism was established to collect the data recorded, and analysis of the data was only able to proceed several months later. However, a web-based system ('FluPut') was successfully established at very short notice to collect daily throughput data from each flu clinic. Data included: whether the clinic was operating, and if so, the total number of patients assessed, the proportion referred to emergency departments or for admission, and the number of courses of oseltamivir dispensed.

\section{Intensive care surveillance}

Although the disease proved to be relatively mild in most of those with infection, anecdotal reports indicated that intensive care units (ICUs) were caring for an extraordinarily large number of relatively young patients, many of them pregnant, with severe and very rapidly progressing respiratory failure requiring advanced mechanical ventilatory support or even extra-corporeal membrane oxygenation (ECMO). The need for surveillance capabilities for sicker patients admitted to hospital wards and ICUs had been anticipated in pre-pandemic planning, but mechanisms to collect such data in a timely fashion had not been established. An existing near real-time general and ICU-bed occupancy monitoring system did not collect adequate information describing the reason for admission to allow influenza patients to be distinguished from all other patients.

However, a new web-based system to collect a daily aggregate census of the numbers of patients admitted to each NSW ICU with influenza and influenza-related complications, as well as numbers of pregnant patients and patients requiring ECMO support was found to be valuable. A separate existing register, established and operated by the Australia and New Zealand Intensive Care Society, was used to collect clinical information on ICU patients with confirmed influenza.

\section{Paediatric hospital surveillance}

A similar clinical register of children admitted to the three children's hospitals in NSW was also established. Clinical 
information and follow-up outcome information was collected by a small team of nurses at each hospital for all patients admitted with a laboratory-confirmed test of influenza.

\section{Deaths}

Deaths data were available by direct follow-up of hospitalised cases, from information supplied by NSW coroners and from death certificate data. The surveillance of death certificates uses the medical certificate cause of death information from the NSW Registry of Births, Deaths and Marriages to assess all-cause mortality and excess pneumonia and influenza deaths due to circulating influenza viruses.

\section{General practice-based surveillance}

Given the relatively mild nature of the disease, and public health messages that encouraged people with mild symptoms to remain at home, it was necessary to rapidly institute some additional forms of surveillance data in order to address otherwise very limited knowledge of the level of illness and degree of spread in the wider community. A GP sentinel surveillance system covering approximately 30 practices was established in just 2 weeks during July. The principle behind sentinel surveillance is that collection of data by a relatively small number of GPs is able to provide a representation of the number of people attending their GP. Selected general practices across NSW were invited by local public health units to participate in limited data collection. Each participating practice recorded the total number of patients and the number presenting with influenza-like illness on a selected day each week. Of the 660 patients who attended one of the participating GPs, 140 had a nose and throat swab collected. These data were collated using NetEpi.

This surveillance system revealed that at its peak in the third week of July, approximately $10 \%$ of all presentations to participating GPs were for influenza-like illnesses, and nearly one-third of the swabs taken from these patients confirmed infection with pandemic (H1N1) 2009 influenza. In the final week of July and the first week of August, the GP sentinel surveillance system data showed a dramatic drop in influenza presentations, which was mirrored by a slower but nevertheless pronounced drop in presentations to emergency departments and flu clinics.

\section{Work place surveillance}

Arrangements were also made for a major Australian employer with a very large and distributed workforce to forward daily counts of workers absent for more than 3 days, by postcode of place of employment. Because of the restriction on days absent, this reporting appears to show the incidence of somewhat more serious illness-causing longer absence. It is also restricted to the working age population. Within those constraints, 2009 information suggested a similar degree of absenteeism to the 2007 seasonal influenza epidemic. This information source needs further evaluation over a longer period.

\section{A role for record linkage}

Record linkage (matching) between the surveillance and laboratory test data contained in the NetEpi database, and non-real-time data on hospital-admitted patients, death certificates and the clinical registers mentioned above was carried out. During future public health emergencies, it would be both feasible and desirable to carry out such matching and consolidation of data about individuals from multiple data sources on a continuous and near real-time basis.

\section{Discussion}

Each phase of the pandemic response placed a different emphasis on the various sources and types of surveillance information which were collected and reported upon: in the DELAY phase, border surveillance and control were deemed most important, while also maintaining vigilance for signs of local community transmission. During the CONTAIN phase, rapid identification of and response to localised outbreaks were paramount, and during the PROTECT phase, the primary requirement was monitoring the impact of the virus on the health-care system, particularly the demand for scarce and highly specialised ICU treatment facilities. Throughout there was a need to gauge the spread of pandemic virus infection in the wider community, and the impact the illness caused on the workforce and other aspects of societal function.

In the initial DELAY and CONTAIN phases, particularly before tests specific for the pandemic virus were developed, a reliable case definition was of paramount importance. The case definition initially only allowed for identification of cases coming into the country; it was later adapted to include the possibility of community transmission. Throughout all phases, case definitions required the presence of fever in the absence of clear contact with confirmed cases. However, relaxation of these case definitions would have resulted in many hundreds more suspect cases, all of whom would have required follow-up.

Communication of surveillance findings remains a challenge. High-level decision makers typically require only high-level summary information, except when dealing with specific issues, when they tend to need highly detailed information about specific issues. Conversely, those responsible for managing smaller regions or more specific aspects of the public health response require summary information at much higher levels of granularity, while those implementing public health interventions tend to need highly-detailed operational 'line listing' reports, rather than aggregated information. Distribution of such low-level, disaggregated information also carries privacy concerns, and it is necessary to ensure that only 
those staff with a need to know have access to such information.

No single form of situation report can simultaneously satisfy all these requirements, and thus communication of surveillance information must be able to be tailored to each recipient's needs. Currently available web technologies, many of them originally developed to facilitate social networking, could be adapted for such purposes. However, implicit in such an approach is the need to automate surveillance reporting as far as possible. This remains a challenge, with the majority of public health emergency situation reports still being assembled by hand. Automatic reporting takes time and very high-level skills to establish, and may not be able to adapt to rapidly changing requirements with sufficient speed. The solution is to develop mechanisms and tools which make the setting up and modification of automated reporting and analysis of surveillance data much faster and easier than it is at present, and to ensure that a skilled cadre of staff familiar with these tools is always available.

\section{Conclusion}

Despite the relatively mild nature of the disease which the pandemic (H1N1) 2009 influenza virus caused in most people, and despite some as yet unmet challenges in the way surveillance is carried out in public health emergencies, there were good returns on the effort and resources invested in planning and capability development prior to and during the emergency. For the first time, we demonstrated that it was possible to organise and effectively orchestrate a large-scale response to a public health emergency, and that that response was effective in delaying and containing the spread of a highly communicable disease. It is important that we continue to make appropriate and sustained investments in public health surveillance, to close the gaps identified during the 2009 influenza pandemic, and to consolidate gains already made. This is important because there will inevitably be other major threats to the public health.

\section{References}

1. Australian Government Department of Health and Ageing. Australian Health Management Plan for Pandemic Influenza 2008. Available from: http://www.health.gov.au/internet/ panflu/publishing.nsf/Content/ahmppi

2. Centers for Disease Control and Prevention (CDC). Swine influenza A (H1N1) Infection in two children - Southern
California, March-April 2009. MMWR Morb Mortal Wkly Rep 2009; 58(15): 400-2.

3. Cohen J. Swine flu outbreak. Out of Mexico? Scientists ponder swine flu's origins. Science 2009; 324: 700-2. doi:10.1126/science.324_700

4. Fraser C, Donnelly CA, Cauchemez S, Hanage WP, Van Kerkhove MD, Hollingsworth TD et al. Pandemic potential of a strain of influenza A (H1N1): early findings. Science 2009; 324: 1557-61. doi:10.1126/science. 1176062

5. NSW Public Health Network. Progression and impact of the first winter wave of the 2009 pandemic H1N1 influenza in New South Wales, Australia. Euro Surveill 2009; 14(42): ii-19365.

6. Biopreparedness Unit NSW Health. Operations at International Borders in NSW during an Influenza Pandemic - Discussion Paper. 2007 (unpublished material).

7. NetEpi Case Manager open source, web-based outbreak database system. Available from: http://netepi.sourceforge.net/ (Cited 29 April 2009.)

8. Novel Swine-Origin Influenza A (H1N1) Investigation Team. Emergence of a novel swine-origin influenza A (H1N1) virus in humans. N Engl J Med 2009; 361: 1-10.

9. Carrat F, Vergu E, Ferguson NM, Lemaitre M, Cauchemez S, Leach $\mathrm{S}$ et al. Time lines of infection and disease in human influenza: a review of volunteer challenge studies. $\mathrm{Am} \mathrm{J}$ Epidemiol 2008; 167(7): 775-85. doi:10.1093/aje/kwm375

10. WHO Technical. Consultation on the severity of disease caused by the new influenza A (H1N1) virus infections. Available from: http://www.who.int/csr/resources/publications/ swineflu/technical_consultation_2009_05_06/en/index.html (Cited 9 May 2009.)

11. Communicable Diseases Network of Australia. H1N1 Influenza 2009 (Human Swine Influenza) Infection 'Contain Phase' Interim Working Guidelines for Australian Public Health Units. Version 3.0A. 3 June 2009.

12. Fielding JE, Higgins N, Gregory JE, Grant KA, Catton MG, Bergeri I et al. Pandemic H1N1 Influenza Surveillance in Victoria, Australia, April-September, 2009. Euro Surveill 2009; 14(42): ii.

13. Communicable Diseases Network of Australia. Influenza Surveillance Reports, 2009. Available from: http://www.health.gov.au/internet/main/publishing.nsf/Content/ cda-ozflu-2009.htm (Cited 29 July 2009.)

14. NSW Health. NSW Health Interim Influenza Action Plan, November 2005. Available at: http://www.health.nsw.gov.au/ pubs/2005/pdf/pandemic_ap.pdf (Cited 29 July 2009.)

15. NSW Health. Weekly Influenza Report, July 2009. Available at: http://www.health.nsw.gov.au/publichealth/infectious/index.asp (Cited 29 July 2009.) 